\title{
In vitro synergistic cytotoxicity of gemcitabine and pemetrexed and pharmacogenetic evaluation of response to gemcitabine in bladder cancer patients
}

\author{
V Mey', E Giovannetti*, , F De Braud², S Nannizzi', G Curigliano², F Verweij ${ }^{2}$, O De Cobelli², S Pece², \\ M Del Tacca' and R Danesi'
}

'Division of Pharmacology and Chemotherapy, Department of Internal Medicine, University of Pisa, 55, Via Roma, 1-56 100, 56 I 26, Pisa, Italy;

${ }^{2}$ Department of Medical Oncology and Division of Urology, European Institute of Oncology, I-20 I 4 I Milan, Italy

The present study was performed to investigate the capability of gemcitabine and pemetrexed to synergistically interact with respect to cytotoxicity and apoptosis in T24 and J82 bladder cancer cells, and to establish a correlation between drug activity and gene expression of selected genes in tumour samples. The interaction between gemcitabine and pemetrexed was synergistic; indeed, pemetrexed favoured gemcitabine cytotoxicity by increasing cellular population in S-phase, reducing Akt phosphorylation as well as by inducing the expression of a major gemcitabine uptake system, the human equilibrative nucleoside transporter-I (hENTI), and the key activating enzyme deoxycytidine kinase (dCK) in both cell lines. Bladder tumour specimens showed an heterogeneous gene expression pattern and patients with higher levels of dCK and hENTI had better response. Moreover, human nucleoside concentrative transporter-I was detectable only in 3/12 patients, two of whom presented a complete response to gemcitabine. These data provide evidence that the chemotherapeutic activity of the combination of gemcitabine and pemetrexed is synergistic against bladder cancer cells in vitro and that the assessment of the expression of genes involved in gemcitabine uptake and activation might be a possible determinant of bladder cancer response and may represent a new tool for treatment optimization.

British Journal of Cancer (2006) 95, 289-297. doi:I0.1038/sj.bjc.6603242 www.bjcancer.com

Published online 25 July 2006

(c) 2006 Cancer Research UK

Keywords: bladder cancer; antifolates; gemcitabine; drug combination; inducible gene expression

Bladder cancer is the fourth cause of death from cancer in the Western world and its incidence and mortality rates have risen steadily over the past decade (Parkin et al, 1999; Jemal et al, 2005).

Transitional cell carcinoma (TCC) comprises more than $90 \%$ of all bladder cancers, and superficial tumours ( $\mathrm{Ta}-\mathrm{T} 1$ stages) account for $70-80 \%$ of newly diagnosed TCC. However, despite the macroscopically complete eradication of the primary lesion, approximately two-thirds of patients will recur, with a worsening of tumour grade and stage (Scher et al, 1997). The most effective approach against superficial bladder cancer is intravesical immunotherapy with Calmette-Guerin Bacillus, but it is associated with serious morbidity and it does not result in a significant survival improvement (Crawford, 2002). Similarly, systemic combination chemotherapy, such as the methotrexate, vinblastine, doxorubicin and cisplatin (MVAC) regimen, has proven activity in advanced bladder cancer, but it exhibits a significant toxicity burden, with a treatment-related mortality of about $4 \%$ (Chester et al, 2004). Therefore, a great deal of interest has been focused on research into new drugs or new drug combinations for intravesical and systemic chemotherapy. In particular, gemcitabine proved to be active both by intravescical instillation treatment, with minimal bladder irritation and systemic administration (Moore et al, 1997;

\footnotetext{
*Correspondence: Dr E Giovannetti; E-mail: e.giovannetti@med.unipi.it
} Revised 5 June 2006; accepted 6 June 2006; published online 25 July 2006
Laufer et al, 2003). Indeed, the gemcitabine-cisplatin combination is effective and safe and it is now frequently administered as first-line therapy against metastatic bladder cancer (von der Maase et al, 2000), although, a significant proportion of patients are not eligible to receive cisplatin chemotherapy (Chester et al, 2004; Li et al, 2005).

Gemcitabine, a cytotoxic pyrimidine deoxynucleoside analogue, is transported into the cell mostly by human equilibrative and concentrative nucleoside transporters (hENT and hCNT, respectively). Cells deficient in hENT1 are highly resistant to gemcitabine (Mackey et al, 2003) while hCNT1 transfection increases gemcitabine sensitivity in pancreatic cancer cell lines (Garcia-Manteiga et al, 2003). As a prodrug, gemcitabine must be phosphorylated to its active diphosphate and triphosphate metabolites, which inhibit ribonucleotide reductase (RR) and DNA synthesis, respectively. Deoxycytidine kinase $(\mathrm{dCK})$ is the rate-limiting enzyme in the biotransformation of nucleoside analogs and the increase in $\mathrm{dCK}$ activity may improve the efficacy of gemcitabine (Blackstock et al, 2001). Moreover, dCK activity was related to dCK mRNA levels in bladder cancer specimens as well as in tumour xenografts, and preliminary data in esophageal tumours demonstrated a significant correlation between dCK expression and response to gemcitabine-based treatment (Sigmond et al, 2004). Furthermore, high expression of the catabolic enzymes 5'-nucleotidase (5'-NT) and cytidine deaminase (CDA) has been found in many cell lines resistant to gemcitabine (Eda et al, 1998; Lotfi et al, 2001). Finally, 
non-small cell lung cancer patients with low expression of the M1 subunit of RR (RRM1) significantly benefited from gemcitabine/ cisplatin neoadjuvant chemotherapy (Rosell et al, 2004), while resistance to gemcitabine was observed both in RRM1 and RRM2 overexpressing cells (Goan et al, 1999; Davidson et al, 2004).

Modulation of enzymes involved in gemcitabine uptake and metabolism may influence drug activity against human tumour cell lines and, among chemotherapeutic drugs, pemetrexed appears to be a potential candidate because of its ability to deplete cellular nucleotide pools by inhibiting nucleotide synthesis (Giovannetti et al, 2005). Indeed, pemetrexed and its polyglutamates are potent, tight-binding inhibitors of folate-dependent enzymes, including thymidylate synthase (TS), dihydrofolate reductase (DHFR), and glycinamide ribonucleotide formyltransferase (GARFT) and show activity against a wide variety of solid tumours, including bladder cancer (Calvert, 2004). This new multitargeted antifolate may enhance the expression of hENT1 and dCK as a compensatory mechanism, potentially favouring gemcitabine activity against cancer cells. Thus, the primary objective of this study was the analysis of cellular and genetic aspects underlying the pharmacological interaction of gemcitabine and pemetrexed in two human bladder cancer cells. Moreover, this study was aimed at providing a preliminary characterisation of the expression pattern of hENT1, hCNT1, dCK, 5'-NT, CDA, RRM1 and RRM2 in surgical specimens of bladder cancer, in order to find a possible association between gene expression and response to gemcitabine treatment.

\section{MATERIALS AND METHODS}

\section{In vitro studies}

Drugs and chemicals Gemcitabine (difluorodeoxycytidine, dFdC) and pemetrexed (multitargeted antifolate, MTA) were generous gifts of Eli Lilly (Indianapolis, IN, USA). Drugs were dissolved in sterile distilled water and diluted in culture medium immediately before use. McCoy's medium, fetal bovine serum (FBS), L-glutamine, penicillin and streptomycin were from Gibco (Gaithersburg, MD, USA). All other chemicals were from Sigma Chemical Co. (St Louis, MO, USA).

Cell lines Human bladder TCC cells T24 and J82 were obtained from American Type Culture Collection (Manassas, VA, USA). Cells were maintained as monolayer cultures in McCoy's (T24) and MEM Eagle (J82) medium, supplemented with $10 \%$ fetal bovine serum, L-glutamine $(2 \mathrm{mM})$, penicillin $\left(50 \mathrm{IU} \mathrm{ml}^{-1}\right)$ and streptomycin $\left(50 \mu \mathrm{g} \mathrm{ml}^{-1}\right)$. Cells were cultivated in $75 \mathrm{~cm}^{2}$ tissue culture flasks (Costar, Cambridge, MA, USA), at $37^{\circ} \mathrm{C}$ in $5 \% \mathrm{CO}_{2}$ and $95 \%$ air, and harvested with trypsin-EDTA when they were in logarithmic growth.

\section{Assay of cytotoxicity}

Cytotoxicity was assessed by the CellTiter 96 Non-radioactive cell proliferation kit (Promega, Madison, MA, USA) based on the cellular metabolism of the tetrazolium compound MTT. Cells $\left(5 \times 10^{4}\right.$ well $\left.^{-1}\right)$ were seeded in $1 \mathrm{ml}$ of medium in a 12-well plate and allowed to attach for $24 \mathrm{~h}$. Cells were treated with: (1) gemcitabine $(0.3 \mathrm{nM}-33.3 \mu \mathrm{M})$ for $1,6,24$ and $48 \mathrm{~h}$; (2) pemetrexed $(2.1 \mathrm{~nm}-212.1 \mu \mathrm{M})$ for $1,6,24$ and $48 \mathrm{~h}$; (3) gemcitabine for $1 \mathrm{~h}$, followed by a 24-h washout in drug-free medium, and then pemetrexed for $24 \mathrm{~h}$; (4) pemetrexed for $24 \mathrm{~h}$, followed by a 24-h washout in drug-free medium, and then gemcitabine for $1 \mathrm{~h}$. At the end of drug exposure, sample processing was performed as indicated by the manufacturer. Cell growth inhibition was expressed as the percentage of the $570 \mathrm{~nm}$ absorbance relative to untreated control cultures, measured with a microplate reader (Multiskan Spectrum, Vantaa, Finland), and the 50\% inhibitory concentration of cell growth $\left(\mathrm{IC}_{50}\right)$ was calculated by sigmoid inhibition model (GraphPad PRISM version 4.0; Intuitive Software for Science, San Diego, CA, USA).

Drug interaction was assessed at a fixed $1: 1$ concentration ratio of gemcitabine-pemetrexed by using the combination index (CI) of Chou et al (1994), where $\mathrm{CI}<1, \mathrm{CI}=1$ and $\mathrm{CI}>1$ indicated synergistic, additive and antagonistic effects, respectively. Data analysis was performed by the Calcusyn software (Biosoft, Oxford, UK).

\section{Cell cycle analysis and apoptosis}

Cells $\left(10^{6}\right.$ well $\left.^{-1}\right)$ were plated in $10 \mathrm{ml}$ in $100-\mathrm{mm}$ Petri dishes (Costar) and allowed to grow for $24 \mathrm{~h}$. Cells were treated with gemcitabine $(1 \mathrm{~h})$, pemetrexed $(24 \mathrm{~h})$, and their combinations at concentrations corresponding to $\mathrm{IC}_{50}$ levels and were harvested immediately after the end of drug exposure or allowed to grow for additional $24 \mathrm{~h}$ in drug-free medium. Then cells were washed twice with PBS and DNA was stained with a solution containing propidium iodide $\left(25 \mu \mathrm{g} \mathrm{ml}^{-1}\right)$, RNase $\left(1 \mathrm{mg} \mathrm{ml}^{-1}\right)$ and NonidetP40 (0.1\%). Samples were kept on ice for $30 \mathrm{~min}$ and cytofluorimetry was performed using a FACScan (Becton Dickinson, San José, CA, USA). Data analysis were carried out with the CELLQuest (Becton Dickinson) and Modfit softwares (Verity Software, Topsham, ME, USA).

Apoptosis was evaluated in cells treated with gemcitabine, pemetrexed and their combinations at $\mathrm{IC}_{50}$ levels, as described in 'Assay of Cytotoxicity'. At the end of incubation, cells were washed twice with PBS and fixed in $4 \%$ buffered paraformaldehyde for $15 \mathrm{~min}$. Cells were resuspended and incubated for further $15 \mathrm{~min}$ in a solution containing $8 \mu \mathrm{g} \mathrm{ml}^{-1}$ bisbenzimide chloride. Cells were spotted on glass slides and examined by fluorescence microscopy (Leica, Berlin, Germany). A total of 200 cells from randomly chosen microscopic fields were counted and the percentage of cells displaying chromatin condensation and nuclear fragmentation relative to the total number of counted cells (apoptotic index) was calculated.

\section{Assay of Akt phosphorylation}

Akt protein phosphorylation after gemcitabine or pemetrexed treatment, described above for cell cycle analysis, was assayed with a P-Ser473 specific ELISA and normalised to the total Akt content following the manufacturer's instructions (BioSource International, Camarillo, CA, USA). P-Ser473 Akt and Akt total concentrations were calculated from standard curves and values of P-Ser473 Akt were normalised for total Akt and protein content, which was measured with the Lowry reagent (Sigma), as described previously (Giovannetti et al, 2005).

\section{Quantitative PCR analysis of cell lines}

Cells were treated with gemcitabine and pemetrexed at $\mathrm{IC}_{50}$ and $\mathrm{IC}_{10}$ concentration values. RNA was extracted with the QiaAmp RNA mini Kit (Qiagen, San Diego, CA, USA) according to the manufacturer's protocol, dissolved in $10 \mathrm{~mm}$ dithiothreitol and $200 \mathrm{U} \mathrm{ml}^{-1}$ RNase inhibitor in Rnase-free water, and measured by absorbance reading at $260 / 280 \mathrm{~nm}$, using the Uvikon- 940 spectrophotometer (Kontron, Milan, Italy). RNA $(1 \mu \mathrm{g})$ was reverse transcribed at $37^{\circ} \mathrm{C}$ for $1 \mathrm{~h}$ in $50-\mu \mathrm{l}$ reaction volume containing $0.8 \mathrm{~mm}$ dNTPs, $200 \mathrm{U}$ of MMLV-RT, $40 \mathrm{U}$ of RNase inhibitor and $0.05 \mu \mathrm{g} \mathrm{ml}^{-1}$ of random primers. The resulting cDNA was amplified by quantitative PCR with the Applied Biosystems 7900HT sequence detection system (Applied Biosystems, Foster City, CA, USA). PCR reactions were performed in triplicate using $5 \mu \mathrm{l}$ of cDNA, $12.5 \mu \mathrm{l}$ of TaqMan Universal PCR Master Mix, $2.5 \mu \mathrm{l}$ of probe and $2.5 \mu \mathrm{l}$ of forward and reverse primers in a final volume of $25 \mu \mathrm{l}$. Samples were amplified using an initial incubation 
at $50^{\circ} \mathrm{C}$ for $5 \mathrm{~min}$, followed by incubation at $95^{\circ} \mathrm{C}$ for $10 \mathrm{~min}, 40$ cycles of denaturation at $95^{\circ} \mathrm{C}$ for $15 \mathrm{~s}$ followed by annealing and extension at $60^{\circ}$ for $1 \mathrm{~min}$.

Forward and reverse primers and probes for dCK (NM_000788), cN-II 5'-NT (NM_012229), CDA (NM_001785), TS (NM_0010711), DHFR (NM_000791) and GARFT (NM_000819) were designed on the basis of the gene sequence obtained from the GeneBank database with the Primer Express software (Applied Biosystems, V.2.0), as previously described (Giovannetti et al, 2005); while primers and probes for hENT1 (NM_004955), hCNT1 (NM_004213) and for the regulatory M1 (NM_001033), and catalytic M2 (NM_001034) subunits of RR were obtained from Applied Biosystems Assay-on-Demand ${ }^{\mathbb{R}}$ products (Hs00168784, Hs00188418, Hs0035724 and Hs00191940).

Amplifications were normalised to glyceraldehyde 3-phosphate dehydrogenase (GAPDH), and quantitation of gene expression in treated cells was performed using the $\Delta \Delta C_{\mathrm{T}}$ calculation, where $C_{\mathrm{T}}$ is the threshold cycle. The amount of target gene, normalised to GAPDH and relative to the calibrator (untreated control cells), was reported as percent variation of $2^{-\Delta \Delta C_{\mathrm{T}}}$ with respect to control.

\section{Modulation of gemcitabine uptake, metabolism and cytotoxicity}

Cells plated and treated with gemcitabine alone or in combination with pemetrexed $(0.3 \mathrm{nM}-33.3 \mu \mathrm{M})$ as described in 'Assay of Cytotoxicity', were simultaneously exposed to 2 '-deoxycytidine $(10 \mu \mathrm{M})$, to inhibit drug activation by phosphorylation (dCK), to the specific hENT1 inhibitor nitrobenzylthioinosine (NBMPR, $100 \mathrm{nM}$ ) or to dipyridamole, a non-specific inhibitor of nucleoside transporters, used at concentration of $10 \mu \mathrm{M}$, as previously described (Giovannetti et al, 2005).

\section{Ex vivo studies on human samples of bladder cancer}

Patient characteristics and treatment In all, 12 bladder cancer patients were evaluated in this study. Median age was 61 years (range, 32-75); five were males and seven females. Six patients $(50.0 \%)$ had stage I, while $16.7 \%$ had stage II and $33.3 \%$ stage III disease at the time of diagnosis.

Chemotherapy treatment consisted of intravesical gemcitabine administered every $7 \pm 1$ day for 6 consecutive weeks. Gemcitabine was reconstituted in $0.9 \% \mathrm{NaCl}$ solution for injection, to a concentration of $40 \mathrm{mg} \mathrm{ml}^{-1}$ and $2000 \mathrm{mg}$ were delivered intravescically, through a urethral catheter, which was then removed. The patient was asked to avoid urination for $1 \mathrm{~h}$ after gemcitabine instillation.

Tissue sampling and RNA extraction The experimental protocol was approved by the local Ethics Committee and patients were required to sign a consent form to use pathological specimens for research purposes, prior to their enrolment.

Tissue sampling was performed immediately after transurethral resection, 7 days before the first instillation of gemcitabine. Tumours were fragmented, placed in optimal cutting temperature (OCT) solution (Sakura Finetek Inc., Torrance, CA, USA), and stored at $-80^{\circ} \mathrm{C}$ until extraction of RNA by the TRI REAGENT LS (Sigma) from tumour fragments homogenised at $4^{\circ} \mathrm{C}$. RNA concentration was determined by absorbance reading at $260 \mathrm{~nm}$.

Quantitative PCR analysis in tissue samples RNA extracted from tissue specimens was reverse transcribed in a $50 \mu \mathrm{l}$ reaction volume and the resulting cDNA was amplified by quantitative, real-time PCR, as described above in 'Quantitative PCR analysis of cell lines'. Preliminary experiments were carried out with dilutions of cDNA obtained from Quantitative PCR Human Reference Total RNA (Stratagene, La Jolla, CA, USA) to determine the primer concentrations that give the minimum s.d. among $C_{\mathrm{T}}$ values and to demonstrate that the efficiencies of amplification of targets and reference genes (GAPDH) were similar. All reactions were performed in triplicate, with appropriate nontemplate controls, and the coefficient of variation (CV) was $<1 \%$ for all replicates.

\section{Statistical methods}

All experiments were performed in triplicate and data were expressed as mean values \pm s.d. and were analysed by Student's $t$-test or ANOVA, followed by the Tukey's test for multiple comparisons. Demographic and clinical informations were obtained from medical records. Patients were endoscopically evaluated for response within 1-4 weeks after the end of treatment, using a marker lesion, as previously described (Lamm et al, 1995). Indeed, trials conducted within the EORTC GU and MRC Group using marker tumours provided evidence that this approach is safe and ethically acceptable (Van der Meijden et al, 1996).

The relationship between expression of target genes and response to treatment was evaluated by stratifying patients by clinical outcome and gene expression values. Data were analysed using SPSS/PC + 11.5 statistical software (LEAD Technologies, NC, USA) and statistical significance was set at $P<0.05$.

\section{RESULTS}

\section{Cytotoxicity and pharmacological interaction}

Gemcitabine was cytotoxic against T24 and J82 bladder cancer cells, with $\mathrm{IC}_{50} \mathrm{~s}$ of $91.7 \pm 5.1$ and $4366.7 \pm 833.3 \mathrm{nM}$, after $1 \mathrm{~h}$ treatment, and $6.1 \pm 0.4$ and $5.7 \pm 1.0 \mathrm{~nm}$ after $24 \mathrm{~h}$ exposure, respectively (Figure 1 and Table 1). A dose-dependent inhibition of cell growth was also observed in both cell lines after 24 and 48-h pemetrexed exposures, with a higher sensitivity of T24 than 882 cells.

As the CI method recommends a ratio of $\mathrm{IC}_{50} \mathrm{~s}$ values at which drugs are equipotent, combination studies were performed at fixed $1: 1$ (gemcitabine:pemetrexed) concentration ratios in both bladder cancer cells. The sequential exposure of cell lines to pemetrexed followed by gemcitabine reduced the $\mathrm{IC}_{50} \mathrm{~s}$ of gemcitabine to $10.7 \pm 0.7$ and $100.0 \pm 7.3 \mathrm{nM}$, in T24 and J82 cells, respectively, while the $\mathrm{IC}_{50}$ s resulting from the reverse sequence were $47.3 \pm 3.7$ and $83.3 \pm 9.7 \mathrm{~nm}$ (Figure 1). The analysis of drug interaction revealed a strong synergistic $(\mathrm{CI}<0.3)$ at mid- to high fractions effects using both schedules in T24 and J82 cells, whereas CI values at fractional effects of 0.25 were close to 1 , indicating moderate synergism or additivity, and CI values at frational effects of 0.10 displayed some antagonistic effects. The sequence pemetrexed $\rightarrow$ gemcitabine proved to be the most effective at all drug concentrations in T24 cells, while both sequences were almost equivalent on $\mathrm{J} 82$ cells (Figure 2).

\section{Cell cycle activity}

Pemetrexed was able to affect the cell cycle of bladder cancer cells (Table 2). In particular, the percentage of T24 and J82 cells in the S-phase increased significantly $(P<0.05)$ after treatment with pemetrexed for $24 \mathrm{~h}$. The same effect on T24 cell cycle was observed after a 1-h treatment with gemcitabine. In contrast flow cytometry did not show significant perturbation after gemcitabine exposure in J82 cells (Table 2). Furthermore, drug combinations demonstrated that both schedules increased the percentage of cells in the S-phase, while in the J82 cells there was a similar reduction in the G1 phase (Table 2).

\section{Induction of apoptosis}

Bladder cancer T24 and J82 cells exposed to pemetrexed, gemcitabine and their combinations presented typical apoptotic 
T24
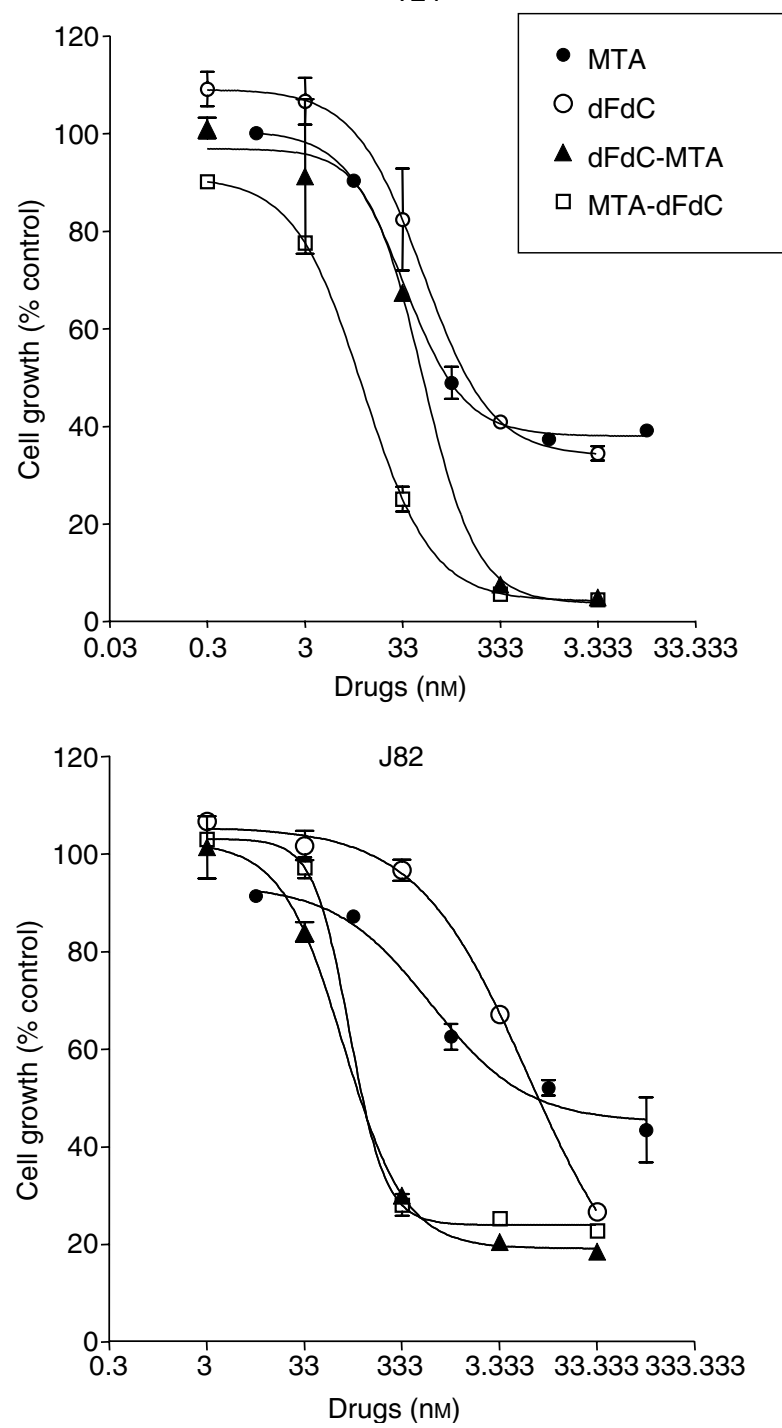

Figure I Concentration-dependent cytotoxicity of gemcitabine (dFdC), pemetrexed (MTA), and their combinations in T24 and J82 bladder cancer cells. Each data point represents the percentage of proliferating cells with respect to untreated control and is the average of three independent experiments. Bars, s.d.

morphology with cell shrinkage, nuclear condensation and fragmentation, and rupture of cells into debris. Furthermore, the occurence of apoptosis was significantly higher in pemetrexedtreated cells $v s$ controls, whereas gemcitabine exposure was associated with a lower percentage of apoptotic cells. In each case, the drug combinations significantly increased the apoptotic index of bladder cancer cells with respect to controls (Figure 3). Finally, both drug combinations significantly increased the apoptotic index of T24 cells with respect to gemcitabine-treated cells $(P<0.05)$.

\section{Inhibition of Akt phosphorilation}

Pemetrexed and gemcitabine significantly reduced the amount of phosphorylated Akt in T24 cells. In J82 cells, the amount of the phosphorylated Akt was decreased up to $-73.9 \%$ by pemetrexed $(P<0.05)$, while gemcitabine was unable to modulate the activation of Akt (Figure 4).

\section{Gene expression and chemosensitivity}

The relative expression of $\mathrm{dCK}$ and hENT1 was higher in T24 and J82 cells (dCK, 0.89 vs 0.82 and hENT1, 0.88 vs 0.85 ). Therefore, the lower chemosensitivity of J82 cells with respect to T24 cells appeared likely dependent on lower expression of genes encoding for hENT1 and dCK, which are involved in drug transport and activation, respectively. A similar correlation was found between the $\mathrm{IC}_{50}$ values of pemetrexed and the target enzyme TS, its relative expression being higher (J82) as compared to T24 cells (TS, 1.02 vs 0.83 ).

\section{Modulation of dCK, hENT1, TS and GARFT gene expression}

Pemetrexed significantly increased hENT1 expression in both cell lines $(P<0.05)$. In particular, a 24 -h pemetrexed exposure at its $\mathrm{IC}_{50} \mathrm{~s}$ levels resulted in a three-fold increase in hENT1 expression in J82 cells (Figure 3). Similar results were observed for dCK, which expression was increased by pemetrexed up to $57.7 \%$ (T24 cells) and $68.2 \%$ (J82 cells), respectively (Figure 3 ) while at $\mathrm{IC}_{10}$ pemetrexed levels here was only a minimal enhancement of hENT1 expression in J82 cells. Moreover, gemcitabine exposure modulated TS and GARFT expression in both cell lines. In particular, TS expression was significantly decreased up to -81.7 and $-74.0 \%$ in J82 and T24 cells, respectively. Similar results on GARFT were observed at gemcitabine concentration corresponding to its $\mathrm{IC}_{50}$, GARFT expression being reduced up to $-36.04 \%$ in J82 cells, while no significant changes were observed in T24 cells (Figure 3 ).

\section{Effect of inhibition of gemcitabine metabolism and transport on cytotoxicity}

A key role for dCK and hENT1 on sensitivity of bladder cell lines to gemcitabine was demonstrated by the increase in $\mathrm{IC}_{50}$ values after simultaneous treatment with their inhibitors (Table 3). In particular, incubation with both dipyridamole and NBMPR resulted in up to 49 -fold increase in $\mathrm{IC}_{50}$ s, suggesting a pivotal role for hENT1 in gemcitabine uptake. In contrast, the use of sequential administration of gemcitabine and pemetrexed partially prevented the reduction of cytotoxic activity by simultaneous administration of deoxycytidine in both cell lines. Similar results were obtained for both schedules with dipyridamole and NBMPR in T24 cells. However, the use of the drug combinations, totally protected $\mathrm{J} 82$ cells from the reduction of antiproliferative effect caused by the inhibition of hENT1 (Table 3).

\section{Clinical outcome and response to chemotherapy}

Clinical data are available from 12 patients with bladder TCC, whose tumour specimens underwent a pathologic examination and were stored in the tissue bank. Patients' follow-up ranged from 5 to 16 months (median 10.5 months) after surgery. All patients received gemcitabine, as described above, and were evaluable for response; two complete responses $(16.7 \%)$ and 10 stable diseases (83.3\%) were observed.

\section{Gemcitabine-related gene expression levels in patients}

The plot on Figure 5 shows the variability of gene expression observed in patients. The results of gene expression analysis of tissue samples showed that dCK, $5^{\prime}-\mathrm{NT}$, CDA, RRM1, RRM2 and hENT1 mRNAs were detectable in all samples, while hCNT1 mRNA was detectable in only three patients. The gene expression profile of patients showed a variable pattern. In particular, dCK was the gene displaying the most pronounced variability (from 0.611 to 1.095 ), while the variability of hENT1 $(1.094 \pm 0.102), 5^{\prime}-\mathrm{NT}(1.010 \pm 0.053), \mathrm{CDA}(0.911 \pm 0.058), \mathrm{RRM} 1$ 
Table I Cytotoxic effect and pharmacological interaction of gemcitabine and pemetrexed against bladder cancer cell lines

\begin{tabular}{|c|c|c|c|c|}
\hline \multirow{2}{*}{ Times (h) } & \multicolumn{4}{|c|}{${ } C_{50}$ values $(\mathrm{nM})^{a}$} \\
\hline & \multicolumn{2}{|c|}{ T24 } & \multicolumn{2}{|c|}{ J82 } \\
\hline $\begin{array}{r}1 \\
6 \\
24 \\
48\end{array}$ & $\begin{array}{r}91.7 \pm 5.1 \\
35.2 \pm 2.9 \\
6.1 \pm 0.4 \\
2.1 \pm 0.4\end{array}$ & $\begin{array}{c}6392.9 \pm 958.9 \\
156.6 \pm 26.6 \\
64.9 \pm 5.3 \\
22.5 \pm 2.8\end{array}$ & $\begin{array}{c}4366.7 \pm 833.3 \\
166.7 \pm 33.3 \\
5.7 \pm 1.0 \\
5.2 \pm 0.8\end{array}$ & $\begin{array}{c}38194.0 \pm 7638.8 \\
25642.2 \pm 5384.8 \\
2566.9 \pm 339.4 \\
63.6 \pm 4.2\end{array}$ \\
\hline 48 & \multicolumn{4}{|c|}{$\mathrm{Cl}$ values $^{\mathrm{b}}$} \\
\hline $\mathbf{F a}$ & Gemcitabine-Pemetrexed & Pemetrexed-Gemcitabine & Gemcitabine-Pemetrexed & Pemetrexed-Gemcitabine \\
\hline $\begin{array}{l}0.50 \\
0.75 \\
0.90\end{array}$ & $\begin{array}{l}0.80 \\
0.25 \\
0.09\end{array}$ & $\begin{array}{l}0.17 \\
0.09 \\
0.05\end{array}$ & $\begin{array}{l}0.04 \\
0.03 \\
0.05\end{array}$ & $\begin{array}{l}0.05 \\
0.05 \\
0.09\end{array}$ \\
\hline
\end{tabular}

${ }^{\mathrm{a}} \mathrm{C}_{50}$ s were calculated as mean values \pm s.d. of at least three $\mathrm{MTT}$ independent experiments after $2,6,24$ and $48 \mathrm{~h}$ of continuous exposure. ${ }^{\mathrm{b}} \mathrm{Combination}$ Index $(\mathrm{Cl})$ values were calculated as mean values from three separate experiments, at fraction affected (FA) of 0.50, 0.75 and 0.90 in cells exposed to gemcitabine and pemetrexed combinations, as explained in the Materials and methods section.
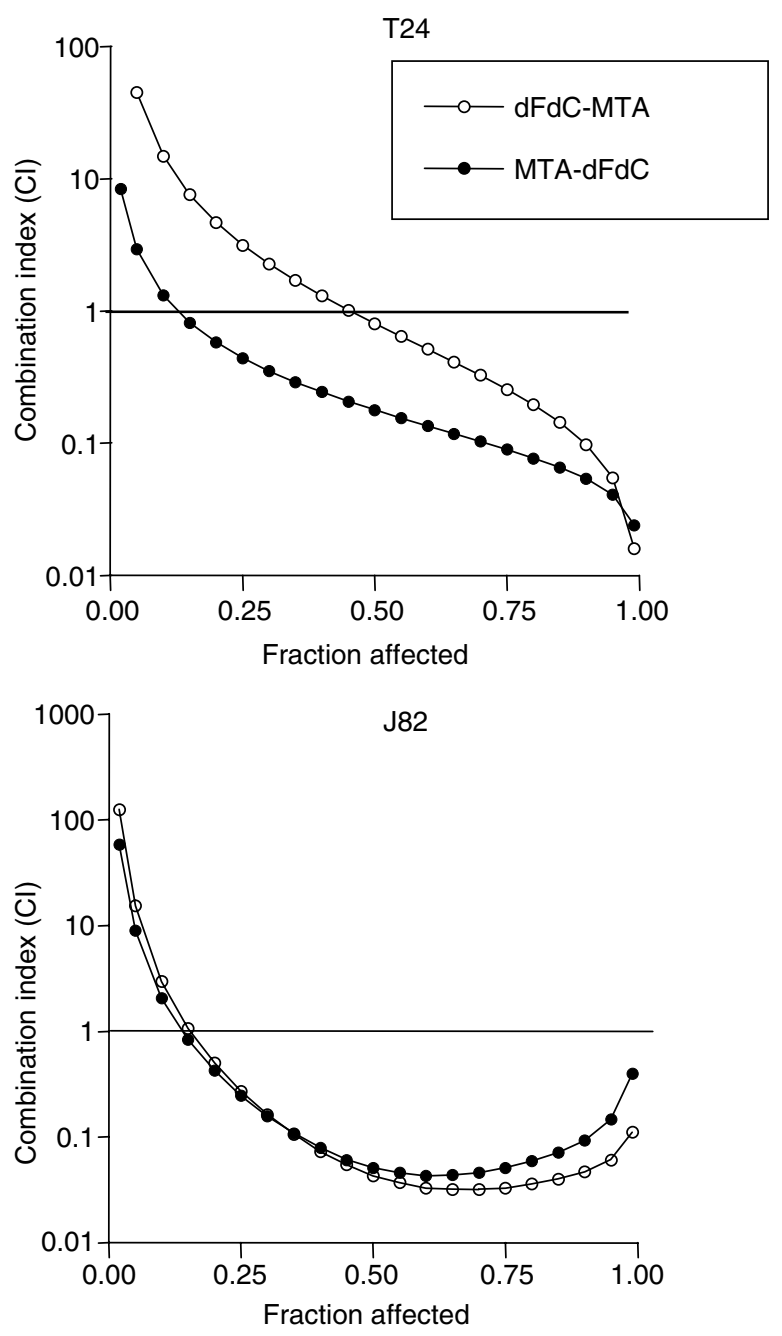

Figure 2 Isobologram analysis of pharmacologic interaction of gemcitabine (dFdC) - pemetrexed (MTA) combinations in T24 and 382 cells.

$(0.988 \pm 0.023)$, and RRM2 (0.924 \pm 0.051$)$, was moderate, suggesting a possible stratification of patients on the basis of their expression profile to create homogeneous groups with different likelihood to respond to gemcitabine treatment. Finally, no apparent relationships among the expression of different genes within individual patients were observed.

\section{Association between clinical outcome and gene expression levels}

A significant relationship was observed between clinical response and expression levels of selected genes (Table 4). In particular, mean values of dCK and hENT1 were significantly higher in patients who had a complete pathological response. Furthermore, hCNT1 expression was detectable only in three patients of whom two presented complete response. However, the other patient with detectable hCNT1 expression presented the lowest level of dCK expression $(0.611 \pm 0.016)$.

\section{DISCUSSION}

Despite the recent advances in the use of chemotherapy in both local and metastatic bladder cancer, long-term, disease-free survival rates remain disappointing. During the past decade, gemcitabine gained widespread use for the treatment of bladder cancer (Moore et al, 1997; Fechner et al, 2003; Muramaki et al, 2004). Moreover, gemcitabine has shown single-agent response rates of $28-36 \%$ in previously untreated metastatic bladder patients, with mild myelosuppression (Chester et al, 2004). The clinical activity of gemcitabine observed in the present work by the data on complete response and stable disease rates, which were 16.7 and $83.3 \%$, respectively, is in agreement with published data.

Nevertheless, there is a continuing need to develop more effective cytotoxic chemotherapy regimens, searching for agents with activity against bladder cancer and low toxicity, as well as to identify molecular markers that are predictive of response, in order to select chemotherapeutic agents best suited for the individual treatment of patients.

Among new drugs, pemetrexed has demonstrated its activity against a variety of tumour types, including bladder cancer, and it is generally well tolerated (Fechner et al, 2003).

In preclinical studies, the combination of pemetrexed and gemcitabine yielded conflicting results. Studies on colorectal cancer cell lines HCT-8, LoVo, WiDr, LRWZ and Calu-1 lung cancer cells showed maximal synergistic cytotoxicity when gemcitabine was followed by pemetrexed in cells (Tesei et al, 2002; Adjei, 2002; Giovannetti et al, 2005). On the contrary, other 
Table 2 Cell cycle modulation after drug treatments, followed by 24-h culture in drug-free medium. Values (\%) are means from three independent experiments and the differences $(\Delta)$ are calculated with respect to controls

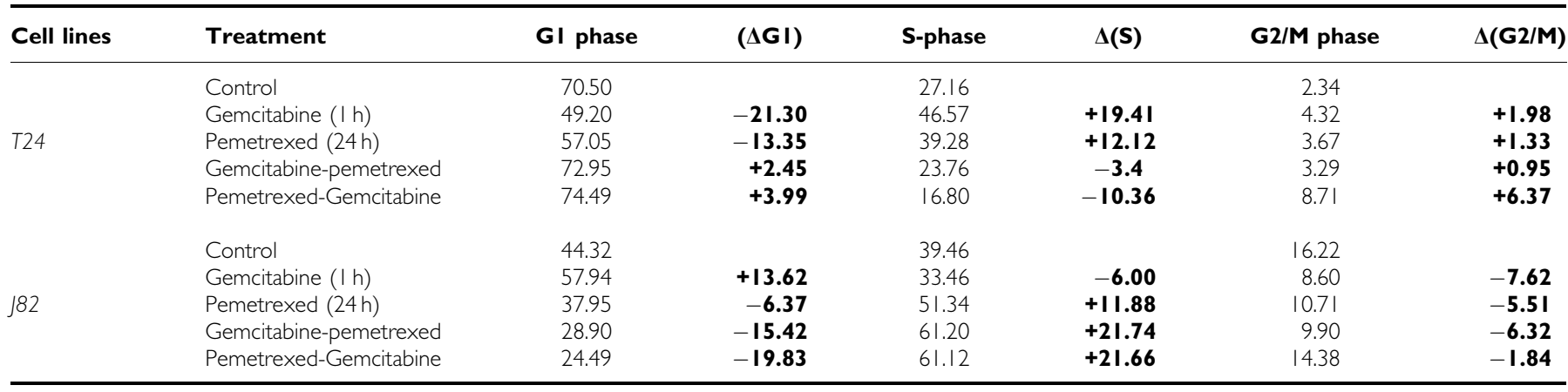

A

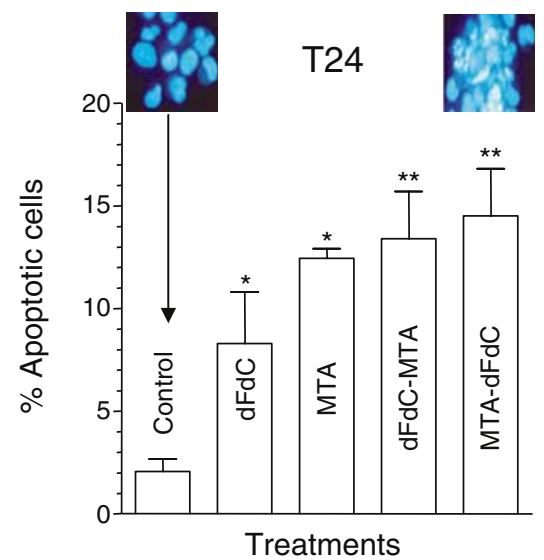

B

T24

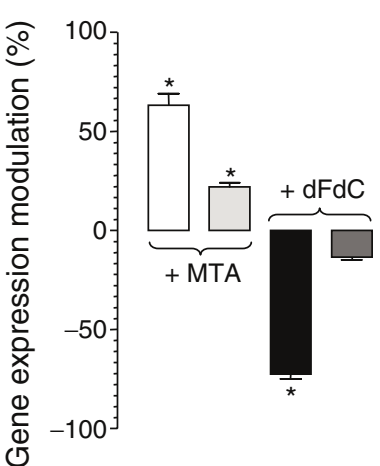

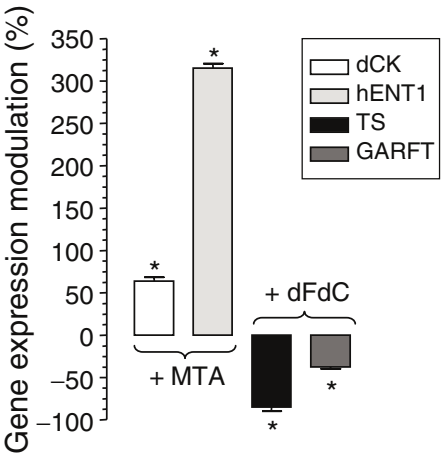

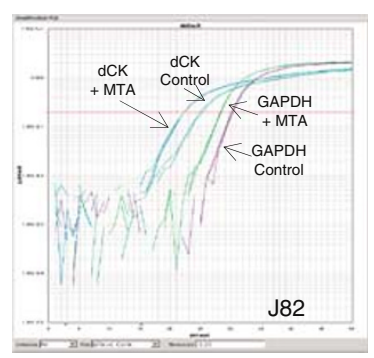

Figure 3 Percentage of cells with damaged DNA after drug treatments with gemcitabine (dFdC), pemetrexed (MTA) and their combinations in both cell lines (A). Upper panels, morphological appearance of control and treated cells. Modulation of hENTI and dCK expression by pemetrexed and modulation of TS and GARFT expression by gemcitabine in comparison with control in T24 and 82 cells (B). Right panel, representative plot of dCK and GAPDH expression in control and treated $\mathrm{j} 82$ bladder cancer cells. Columns, mean values obtained from three independent experiments; bars, s.d. $* P<0.05$ with respect to control, $* * P<0.05$ with respect to gemcitabine.

studies demonstrated that the schedule-dependent synergism was maximal when pemetrexed preceded gemcitabine in HT29 colon cancer cells (Tonkinson et al, 1999), MIA PaCa-2, PANC-1 and Capan-1 pancreatic cancer cells (Giovannetti et al, 2004) and A549 and Calu-6 lung cancer cells (Giovannetti et al, 2005). In vitro experimental data obtained in the present study indicate that in bladder cancer T24 cells the highest chemotherapeutic synergism was observed with the sequence pemetrexed $\rightarrow$ gemcitabine, while both sequences were almost equivalent in $\mathrm{J} 82$ cells.
Understanding the role of cell cycle, apoptosis or other mechanisms involved in cell death or proliferation, may be crucial to improve the therapeutic activity of anticancer drug combinations. The synergistic interaction reported in the present study may be attributed, at least in part, to cell cycle perturbations, inhibition of Akt phosphorilation and modulation of gene expression. Indeed, cell cycle evaluation demonstrated a shift towards the S-phase after pemetrexed exposure, potentially facilitating gemcitabine activity, and gemcitabine-pemetrexed combinations enhanced apoptosis. These findings are in agreement with 
previous data obtained in colon and pancreatic cells, which were synchronised after 24-h pemetrexed exposure, and showed a significant increase of apoptosis after treatment with gemcitabinepemetrexed combinations (Tonkinson et al, 1999; Giovannetti et al, 2004).

One potential antiapoptotic signal transduction system that has been linked to chemoresistance of human cancer cells is the PI3KAkt pathway. In particular, the reduction of phosphorylated Akt correlated with the enhancement of gemcitabine-induced apoptosis and antitumour activity, suggesting that the PI3K-Akt pathway plays a significant role in mediating drug resistance in several pancreatic cancer cells (Bondar et al, 2002). Moreover, an immunohistochemical analysis in patients who underwent curative resection revealed that $\mathrm{p}$-Akt expression was a prognostic factor for overall survival in primary pancreatic adenocarcinoma (Yamamoto et al, 2004). Therefore, the inhibition of Akt might be a possible molecular target for novel therapeutic strategies and the present study demonstrated that pemetrexed significantly decreased the amount of the activated form of Akt.

The present in vitro experimental findings also suggest that the enhancement of hENT1 and dCK expression by pemetrexed could be responsible, at least in part, for the synergistic interaction obtained particularly at mid- to high frational effects with the sequential exposure to gemcitabine in both T24 and J82 bladder cell lines. Indeed, hENT1 and dCK gene expression was not significantly modulated in bladder cancer cells at low fraction affected (0.10 effect level), potentially explaining drug antagonism.

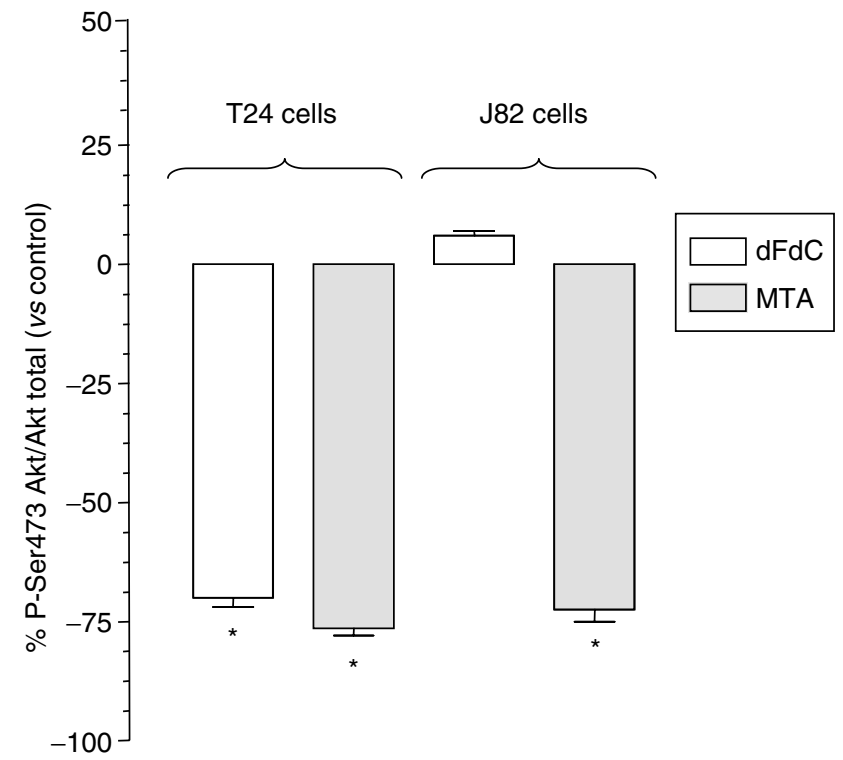

Figure 4 Reduction of P-Ser473 Akt by gemcitabine ( $\mathrm{dFdC}$ ) and pemetrexed (MTA) in bladder cancer cell lines T24 and J82. * $P<0.05$ with respect to control.
However, the modulation of TS and GARFT expression by gemcitabine, potentially favouring pemetrexed activity, could explain the synergistic interaction observed with the gemcitabine $\rightarrow$ pemetrexed combination, especially in J82 cells. These results underline the importance of integrating gene expression analysis for rational development of cytotoxic drug combinations.

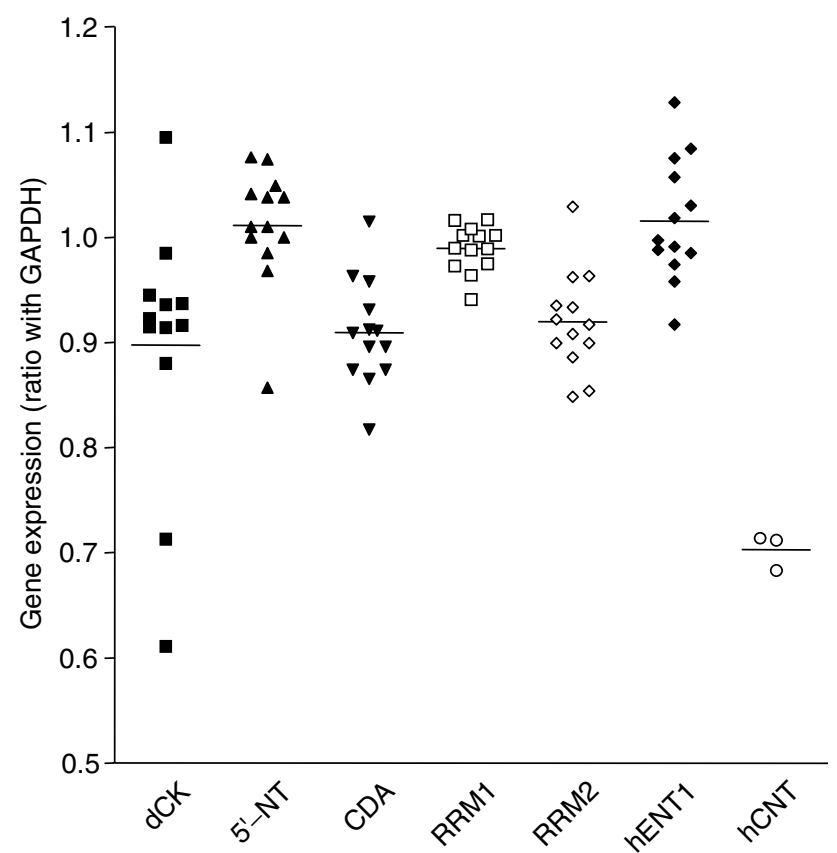

Figure 5 Gene expression of gemcitabine-related genes in 12 bladder cancer patients. Values of gene expression were calculated by the GAPDH/ target gene ratio in triplicate experiments.

Table 4 Correlation between clinical response and gene expression levels in treated patients

\begin{tabular}{lccc}
\hline & \multicolumn{3}{c}{$\begin{array}{c}\text { Gene expression (ratio with GAPDH) } \\
\text { Clinical response }\end{array}$} \\
\cline { 2 - 4 } $\begin{array}{l}\text { Gemcitabine } \\
\text { related genes }\end{array}$ & $\begin{array}{l}\text { Complete } \\
\text { response }\end{array}$ & $\begin{array}{c}\text { Stable } \\
\text { disease }\end{array}$ & $\mathbf{P}$ \\
\hline dCK & $0.925 \pm 0.016$ & $0.892 \pm 0.037$ & 0.037 \\
5'-NT & $1.008 \pm 0.057$ & $1.012 \pm 0.059$ & 0.984 \\
CDA & $0.914 \pm 0.069$ & $0.909 \pm 0.050$ & 0.617 \\
RRMI & $0.986 \pm 0.031$ & $0.990 \pm 0.022$ & 0.674 \\
RRM2 & $0.931 \pm 0.045$ & $0.918 \pm 0.050$ & 0.694 \\
hENTI & $1.166 \pm 0.052$ & $1.021 \pm 0.062$ & 0.040 \\
\hline
\end{tabular}

Values are means \pm s.d. of triplicate experiments. The shaded area allows the identification of significant values.

Table 3 Effects of modulation of dCK and hENT on gemcitabine ( $\mathrm{AFdC}, \mathrm{I}$ ) and gemcitabine-pemetrexed (MTA) combinations IC $50 \mathrm{~S}(\mathrm{nM})$ in T24 and 82 cells. Values are means + s.d. of at least three separate experiments

\begin{tabular}{|c|c|c|c|c|c|}
\hline Cell lines & Treatments & $I C_{50}$ & +Deoxycytidine & +Dipyridamole & +NBMPR \\
\hline
\end{tabular}


Similar results were reported in non-small cell lung cancer cells (Giovannetti et al, 2005), suggesting that modulation of dCK and hENT1 gene expression as well as inhibition of Akt phosphorylation by pemetrexed may be involved in the improvement of gemcitabine therapeutic potential against several cell lines.

Moreover, a recent study by Achiwa et al (2004) demonstrated that increased hENT1 expression was a determinant of gemcitabine sensitivity, while the decreased dCK expression was associated with acquired resistance to gemcitabine in lung cancer cells (Achiwa et al, 2004).

Finally, although the results should be considered very preliminary and the possible prognostic value of other determinants, such as other intracellular $5^{\prime}-\mathrm{NT}$, clearly requires to be evaluated in detail, the present study provides the first evidence of a significant correlation between gemcitabine chemotherapy outcome and hENT1, and dCK expression, in bladder cancer specimens.

These findings are in agreement with a previous study on tissues from patients with advanced pancreatic cancer. Patients with detectable hENT1 expression had significantly longer median survival from gemcitabine initiation than those lacking hENT1 in a proportion of adenocarcinoma cells (median survival, 13 vs 4 months, $P=0.01$ ) (Spratlin et al, 2004).

Similar results were obtained in a pharmacogenetic study on 83 pancreatic cancer patients where PCR analysis demonstrated that overall survival was significantly longer in patients with high hENT1 expression, with respect to patients with low hENT1 levels (median, 25.7, 95\% CI, 17.6-33.7 vs 8.5, 95\% CI, 7.0 - 9.9 month) and the multivariate analysis confirmed the prognostic significance of hENT1 (Giovannetti et al, 2006).

In addition, several in vitro studies demonstrated that several cancer cell lines incorporate gemcitabine mostly via the

\section{REFERENCES}

Achiwa H, Oguri T, Sato S, Maeda H, Niimi T, Ueda R (2004) Determinants of sensitivity and resistance to gemcitabine: the roles of human equilibrative nucleoside transporter 1 and deoxycytidine kinase in non-small cell lung cancer. Cancer Sci 95: 753-757

Adjei AA (2002) Preclinical and clinical studies with combinations of pemetrexed and gemcitabine. Semin Oncol 29: 30-34

Blackstock AW, Lightfoot H, Case LD, Tepper JE, Mukherji SK, Mitchell BS, Swarts SG, Hess SM (2001) Tumor uptake and elimination of 2',2'difluorodeoxycytidine (gemcitabine) after deoxycytidine kinase gene transfer: correlation with in vivo tumor response. Clin Cancer Res 7: $3263-3268$

Bondar VM, Sweeney-Gotsch B, Andreeff M, Mills GB, McConkey DJ (2002) Inhibition of the phosphatidylinositol $3^{\prime}$-kinase-AKT pathway induces apoptosis in pancreatic carcinoma cells in vitro and in vivo. Mol Cancer Ther 1: $989-997$

Calvert AH (2004) Biochemical pharmacology of pemetrexed. Oncology 18: $13-17$

Chester JD, Hall GD, Forster M, Protheroe AS (2004) Systemic chemotherapy for patients with bladder cancer - current controversies and future directions. Cancer Treat Rev 30: 343-358

Chou TC, Motzer R, Tong Y, Bosl G (1994) Computerized quantitation of synergism and antagonism of taxol, topotecan and cisplatin against human teratocarcinoma cell growth: a rational approach to clinical protocol design. J Natl Cancer Inst 86: 1517-1524

Crawford E (2002) Intravesical therapy for superficial cancer: need for more options. J Clin Oncol 20: 3185-3186

Davidson JD, Ma L, Flagella M, Geeganage S, Gelbert LM, Slapak CA (2004) An increase in the expression of ribonucleotide reductase large subunit 1 is associated with gemcitabine resistance in non-small cell lung cancer cell lines. Cancer Res 64: 3761-3766

Eda H, Ura M, F-Ouchi K, Tanaka Y, Miwa M, Ishitsuka H (1998) The antiproliferative activity of DMDC is modulated by inhibition of cytidine deaminase. Cancer Res 58: 1165-1169

Fechner G, Perabo FG, Schmidt DH, Haase L, Ludwig E, Schueller H, Blatter J, Mller SC, Albers P (2003) Preclinical evaluation of radiosensitising
hENT1 and hCNT1 transporters and that treatment of cells with nucleoside transport inhibitors NBMPR or dipyridamole markedly reduced the sensitivity to gemcitabine (Mackey et al, 2003).

The crucial role of hENT1 was confirmed in the present work by the marked reduction of gemcitabine activity with the nucleoside transport inhibitors which was partially circumvented after exposure to drug combinations, confirming the ability of pemetrexed to increase hENT1 expression. Furthermore, transcription analysis in untreated cells suggested the predictive value of expression of both hENT1 and dCK, while, as previously reported in lung and colon cancer cells, a similar correlation was found between TS and chemoresistance to pemetrexed (Sigmond et al, 2003; Giovannetti et al, 2005). Indeed, preclinical studies have also shown that pretreatment dCK expression level could be used as a predictive parameter of tumour sensitivity and a clear correlation between $\mathrm{dCK}$ activity and gemcitabine sensitivity was observed in several tumour xenografts (Kroep et al, 2002). Moreover, dCK mRNA expression in leukaemic blasts at diagnosis was correlated with clinical outcome in patients with acute myeloid leukaemia treated with cytarabine (Galmarini et al, 2003).

In light of these findings, we conclude that (1) gemcitabine and pemetrexed synergistically interact against bladder cancer cells, through suppression of Akt phosphorylation and induction of apoptosis; (2) pemetrexed enhances dCK and hENT1 expression in both cell lines thus suggesting that the sequence pemetrexedgemcitabine is mostly rationally designed; (3) the transcription analysis of gemcitabine-related genes in bladder cancer specimens is feasible and might be useful to help select patients with the highest likelyhood to enjoy complete response after gemcitabine therapy. effect of gemcitabine in p53 mutant and p53 wild type bladder cancer cells. Urology 61: $468-473$

Galmarini CM, Thomas X, Graham K, El Jafaari A, Cros E, Jordheim L, Mackey JR, Dumontet C (2003) Deoxycytidine kinase and cN-II nucleotidase expression in blast cells predict survival in acute myeloid leukaemia patients treated with cytarabine. $\mathrm{Br}$ J Haematol 122: 53-60

Garcia-Manteiga J, Molina-Arcas M, Casado FJ, Mazo A, Pastor-Anglada M (2003) Nucleoside transporter profiles in human pancreatic cancer cells: role of hCNT1 in 2',2'-difluorodeoxycytidine- induced cytotoxicity. Clin Cancer Res 9: 5000-5008

Giovannetti E, Del Tacca M, Mey V, Funel N, Nannizzi S, Ricci S, Orlandini C, Boggi U, Campani D, Del Chiaro M, Iannopollo M, Bevilacqua G, Mosca F, Danesi R (2006) Transcription analysis of human equilibrative nucleoside transporter-1 predicts survival in pancreas cancer patients treated with gemcitabine. Cancer Res 66: 3928-3935

Giovannetti E, Mey V, Danesi R, Mosca I, Del Tacca M (2004) Synergistic cytotoxicity and pharmacogenetics of gemcitabine and pemetrexed combination in pancreatic cancer cell lines. Clin Cancer Res 10: $2936-2943$

Giovannetti E, Mey V, Nannizzi S, Pasqualetti G, Marini L, Del Tacca M, Danesi R (2005) Cellular and pharmacogenetics foundation of synergistic interaction of pemetrexed and gemcitabine in human non-small-cell lung cancer cells. Mol Pharmacol 68: 110-118

Goan YG, Zhou B, Hu E, Mi S, Yen Y (1999) Overexpression of ribonucleotide reductase as a mechanism of resistance to 2,2-difluorodeoxycytidine in the human KB cancer cell line. Cancer Res 59: $4204-4207$

Jemal A, Murray T, Ward E, Samuels A, Tiwari RC, Ghafoor A, Feuer EJ, Thun MJ (2005) Cancer statistics, 2005. CA Cancer J Clin 55: 10-30

Kroep JR, Loves WJ, van der Wilt CL, Alvarez E, Talianidis I, Boven E, Braakhuis BJ, van Groeningen CJ, Pinedo HM, Peters GJ (2002) Pretreatment deoxycytidine kinase levels predict in vivo gemcitabine sensitivity. Mol Cancer Ther 1: 371-376

Lamm DL, van der Meijden APM, Akaza H (1995) Intravesical chemo- and immunotherapy. How do we assess their effectiveness and what are their 
limitations and uses? Proceedings of the Fourth International Bladder Cancer Consensus Conference. Int J Urol 2: 23-35

Laufer M, Ramalingam S, Schoenberg MP, Haisfield-Wolf ME, Zuhowski EG, Trueheart IN, Eisenberger MA, Nativ O, Egorin MJ (2003) Intravesical gemcitabine therapy for superficial transitional cell carcinoma of the bladder: a phase I and pharmacokinetic study. J Clin Oncol 21: $697-703$

Li J, Juliar B, Yiannoutsos C, Ansari R, Fox E, Fisch MJ, Einhorn LH, Sweeney CJ (2005) Weekly paclitaxel and gemcitabine in advanced transitional-cell carcinoma of the urothelium: a phase II Hoosier Oncology Group study. J Clin Oncol 23: 1185-1191

Lotfi K, Mansson E, Chandra J, Wang Y, Xu D, Knaust E, Spasokoukotskaja T, Liliemark E, Eriksson S, Albertioni F (2001) Pharmacological basis for cladribine resistance in a human acute $\mathrm{T}$ lymphoblastic leukaemia cell line selected for resistance to etoposide. Br J Haematol 113: $339-346$

Mackey JR, Mani RS, Selner M, Mowles D, Young JD, Belt JA, Crawford CR, Cass CE (2003) Functional nucleoside transporters are required for gemcitabine influx and manifestation of toxicity in cancer cell lines. Cancer Res 58: 4349-4357

Moore MJ, Tannock IF, Ernst DS, Huan S, Murray N (1997) Gemcitabine: a promising new agent in the treatment of advanced urothelial cancer. $J$ Clin Oncol 15: $3441-3445$

Muramaki M, Miyake H, Hara I, Kawabata G, Kamidono S (2004) Synergistic inhibition of tumor growth and metastasis by combined treatment with TNP-470 and gemcitabine in a human bladder cancer KoTCC-1 model. J Urol 172: 1485- 1489

Parkin DM, Pisani P, Ferlay J (1999) Global cancer statistics. CA Cancer J Clin 49: 33-64

Rosell R, Danenberg KD, Alberola V, Bepler G, Sanchez JJ, Camps C, Provencio M, Isla D, Taron M, Diz P, Artal A, Spanish Lung Cancer Group (2004) Ribonucleotide reductase messenger RNA expression and survival in gemcitabine/cisplatin-treated advanced non-small cell lung cancer patients. Clin Cancer Res 10: 1318-1325

Scher HI, Shimpley WU, Herr HW (1997) Cancer of the bladder. In Cancer Principles and Practice of Oncology DeVita Jr VT, Hellmann S, Rosenberg SA (eds). pp $1300-1322$
Sigmond J, Backus HH, Wouters D, Temmink OH, Jansen G, Peters GJ (2003) Induction of resistance to the multitargeted antifolate Pemetrexed (ALIMTA) in WiDr human colon cancer cells is associated with thymidylate synthase overexpression. Biochem Pharmacol 66: 431-438

Sigmond J, Kroep JR, Loves W, Codacci-Pisanelli G, Peters GJ (2004) Quantitative real time PCR of deoxycytidine kinase mRNA by Light Cycler PCR in relation to enzyme activity and gemcitabine sensitivity. Cancer Lett 213: $173-179$

Spratlin J, Sangha R, Glubrecht D, Dabbagh L, Young JD, Dumontet C, Cass C, Lai R, Mackey JR (2004) The absence of human equilibrative nucleoside transporter 1 is associated with reduced survival in patients with gemcitabine-treated pancreas adenocarcinoma. Clin Cancer Res 10: 6956-6961

Tesei A, Ricotti L, De Paola F, Amadori D, Frassinetti GL, Zoli W (2002) In vitro schedule-dependent interactions between the multitarget antifolate LY231514 and gemcitabine in human colon adenocarcinoma cell lines. Clin Cancer Res 8: 233-239

Tonkinson JL, Worzalla JF, Teng CH, Mendelsohn LG (1999) Cell cycle modulation by a multitargeted antifolate, LY231514, increases the cytotoxicity and antitumor activity of gemcitabine in HT29 colon carcinoma. Cancer Res 59: 3671-3676

Van der Meijden APM, Hall RR, Pavone Macaluso M, Pawinsky A, Sylvester R, Van Glabbeke M (1996) Marker tumour response to the sequential combination of intravesical therapy with Mitomycin C and BCG-RIVM in multiple superficial bladder tumours. Report from the European Organization for Research and Treatment on Cancer-Genitourinary Group (EORTC 30897). Eur Urol 29: 199-203

von der Maase H, Hansen SW, Roberts JT, Dogliotti L, Oliver T, Moore MJ, Bodrogi I, Albers P, Knuth A, Lippert CM, Kerbrat P, Sanchez Rovira P, Wersall P, Cleall SP, Roychowdhury DF, Tomlin I, Visseren-Grul CM, Conte PF (2000) Gemcitabine and cisplatin versus methotrexate. Vinblastine doxorubicin and cisplatin for advanced transitional cell carcinoma of the urothelium. J Clin Oncol 18: 3068-3077

Yamamoto S, Tomita Y, Hoshida Y, Morooka T, Nagano H, Dono K, Umeshita K, Sakon M, Ishikawa O, Ohigashi H, Nakamori S, Monden M, Aozasa K (2004) Prognostic significance of activated Akt expression in pancreatic ductal adenocarcinoma. Clin Cancer Res 10: 2846-2850 